\title{
Research on Properties of Foamed Concrete Reinforced with Small Sized Glazed Hollow Beads
}

\author{
Chi Hu, ${ }^{1,2}$ Hui Li, ${ }^{2}$ Zhongwei Liu, ${ }^{2}$ and Qingyuan Wang ${ }^{1,3}$ \\ ${ }^{1}$ College of Architecture \& Environment, Sichuan University, Chengdu 610064, China \\ ${ }^{2}$ Sichuan College of Architectural Technology, Deyang 618000, China \\ ${ }^{3}$ School of Architecture and Civil Engineering, Chengdu University, Chengdu 610106, China \\ Correspondence should be addressed to Qingyuan Wang; wangqy@scu.edu.cn
}

Received 21 February 2016; Revised 7 April 2016; Accepted 7 April 2016

Academic Editor: Robert Cerný

Copyright (c) 2016 Chi Hu et al. This is an open access article distributed under the Creative Commons Attribution License, which permits unrestricted use, distribution, and reproduction in any medium, provided the original work is properly cited.

\begin{abstract}
Foamed concrete $\left(400 \mathrm{~kg} / \mathrm{m}^{3}\right)$ was prepared through a physical foaming method using ordinary Portland cement (42.5R), vegetable protein foaming agent, fly ash, and glazed hollow beads (GHB, K46) as raw materials. The performance of cement paste as well as the structure and distribution of air voids was characterized by rheometry, SEM, and XRD analyses with imaging software. The effects of GHBs on the compressive strength and thermal conductivity of the foamed concrete sample were also explored. Results show that the proportion of 50-400 $\mu \mathrm{m}$ air voids, average air-void diameter, $28 \mathrm{~d}$ compressive strength, and thermal conductivity of the test sample mixed with $2.4 \mathrm{wt} \% \mathrm{GHBs}$ are $94.44 \%, 182.10 \mu \mathrm{m}, 2.39 \mathrm{MPa}$, and $0.0936 \mathrm{w} /(\mathrm{m} \cdot \mathrm{k})$, respectively. Excessive amount of GHBs $(>2.4 \mathrm{wt} \%)$ increases the amount of air voids with diameter smaller than $50 \mu \mathrm{m}$ in the hardened foamed concrete as well as the degree of open porosity. Moreover, the proportion of 50-400 $\mu \mathrm{m}$ air voids, average air-void diameter, $28 \mathrm{~d}$ compressive strength, and thermal conductivity of the sample mixed with $4.0 \mathrm{wt} \% \mathrm{GHBs}$ are $88.54 \%, 140.50 \mu \mathrm{m}, 2.05 \mathrm{MPa}$, and $0.0907 \mathrm{w} /(\mathrm{m} \cdot \mathrm{k})$, respectively.
\end{abstract}

\section{Introduction}

The construction of high-rise and super high-rise buildings impels the need to reduce the weight of walls; foamed concrete has become one of the hotspots in research of building materials because of the national policy that advocates energy efficiency of buildings [1-6]. Glazed hollow beads (GHBs), a new inorganic thermal insulator, are characterized by spherical hollow structure, closed air voids, vitrified surface, stable physical and chemical properties, low density, low thermal conductivity, and good fluidity $[7,8]$. GHBs are widely applied in coatings, thermal mortar, and thermal insulators [9-16].

Researchers have improved the mechanical properties and thermal conductivity of foamed concrete by adding expanded perlites and fibers. Zhao et al. [17] prepared $900 \mathrm{~kg} / \mathrm{m}^{3}$ foamed concrete by adding expanded perlites; the prepared foamed concrete exhibits a thermal conductivity of $0.1334 \mathrm{w} /(\mathrm{m} \cdot \mathrm{k})$ and a $28 \mathrm{~d}$ compressive strength of $3.2 \mathrm{MPa}$. Chen and Liu [18] prepared $800 \mathrm{~kg} / \mathrm{m}^{3}$ foamed concrete by using ordinary Portland cement (with a $28 \mathrm{~d}$ compressive strength of $72.5 \mathrm{MPa}$ ), high alumina cement $\left(92.4 \% \mathrm{SiO}_{2}\right)$, PP fiber, and EPS fiber. The prepared foamed concrete features a $28 \mathrm{~d}$ compressive strength of $11.0 \mathrm{MPa}$ and a high thermal conductivity of $0.25 \mathrm{w} /(\mathrm{m} \cdot \mathrm{k})$. GHBs are widely added in thermal mortar and insulators; these beads can reduce the density of concrete materials and significantly enhance the thermal insulation properties of mortar and concrete $[9,12$, 13, 15]. Nevertheless, few studies reported the application of GHBs in foamed concrete (GHBFC). Generally, GHBs with small dimension show high compressive strength. Small GHBs demonstrate higher strength and maximally improve the compressive strength of foamed concrete compared with expanded perlites with high thermal insulation property. Moreover, spherical GHBs demonstrate higher dispersion capability than fibers presenting outstanding reinforcement effect and thus can be used to simplify the manufacture of modified concrete materials.

In this study, GHBs were added to GHBFC to partially replace the cement. The effects of GHBs on the fluidity of 
TABLE 1: The primary physical and chemical characters of GHBs.

\begin{tabular}{lccccccccc}
\hline $\begin{array}{l}\mathrm{SiO}_{2} \\
(\%)\end{array}$ & $\mathrm{Al}_{2} \mathrm{O}_{3}(\%)$ & $\mathrm{CaO}(\%)$ & $\mathrm{Fe}_{2} \mathrm{O}_{3}(\%)$ & $\mathrm{K}_{2} \mathrm{O}(\%)$ & $\mathrm{Na}_{2} \mathrm{O}(\%)$ & Compressive strength $(\mathrm{MPa})$ & True density $\left(\mathrm{kg} / \mathrm{m}^{3}\right)$ & $\begin{array}{c}\text { The particle size }(\mu \mathrm{m}) \\
10 \%\end{array}$ & $50 \%$ \\
\hline 70.34 & 16.10 & 9.89 & 0.13 & 0.68 & 0.16 & 41.34 & 460 & 15 & 40 \\
\hline
\end{tabular}

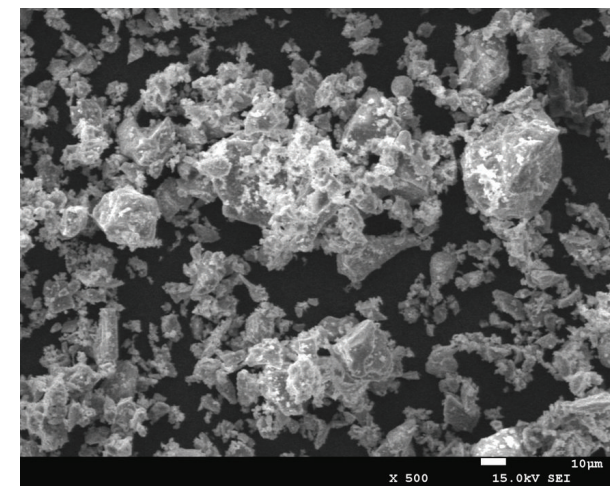

(a) Cements $\times 500$

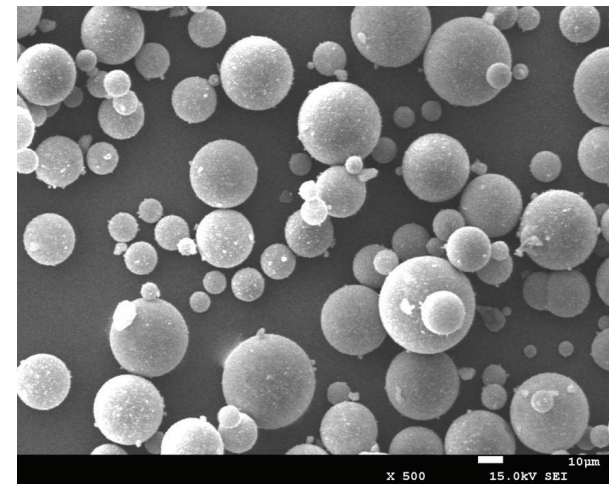

(b) GHBs $\times 500$

FIGURE 1: SEM images of the cements and GHBs mentioned.

cement paste as well as on the structure of air voids and pore walls of foamed concrete were also investigated. Our results provide a reference for production of light foamed concrete with high compressive strength and low thermal conductivity.

\section{Experimental}

2.1. Materials. Ordinary Portland cement ( $\mathrm{PO} 42.5 \mathrm{R}$, in accordance with the Chinese standard, GB 175-2007) was provided by Deyang Lisen Cement Plant. The particle size and surface morphology of the cement are shown in Figure 1(a). The plant protein foaming agent was provided by Sichuan Xinhan Corrosion Protection Engineering Co., Ltd. Level I fly ash was acquired from Jiangyou Thermal Power Plant. GHBs (K46) were produced by Minnesota Mining and Manufacturing (USA). The primary physical and chemical characters of GHBS are listed in Table 1. The particle sizes and surface morphologies of GHBs are shown in Figure 1(b). Particle size distribution (Figure 2) was determined using Mastersizer 2000 (Malvern, England).

2.2. Preparation. All GHBFC specimens were prepared in the laboratory by using a $15 \mathrm{dm}^{3}$ horizontal type mixer (GH15, Beijing Guanggui Jingyan Foamed Concrete Science \& Technology Co., Ltd.) at $25^{\circ} \mathrm{C}$ and under the mixing speed of $40 \mathrm{r} / \mathrm{min}$. The process is detailed as follows:

(1) The foaming agent was diluted with water at 1:15 ratio. The dilution was injected into the bucket of the foamer (ZK-FP-20, Beijing Zhongke Zhucheng Building Materials Co., Ltd.) by using a high-pressure pump. The dilution was placed in the foaming device and subjected to high-pressure air produced by an air compressor to generate uniform fine bubbles.

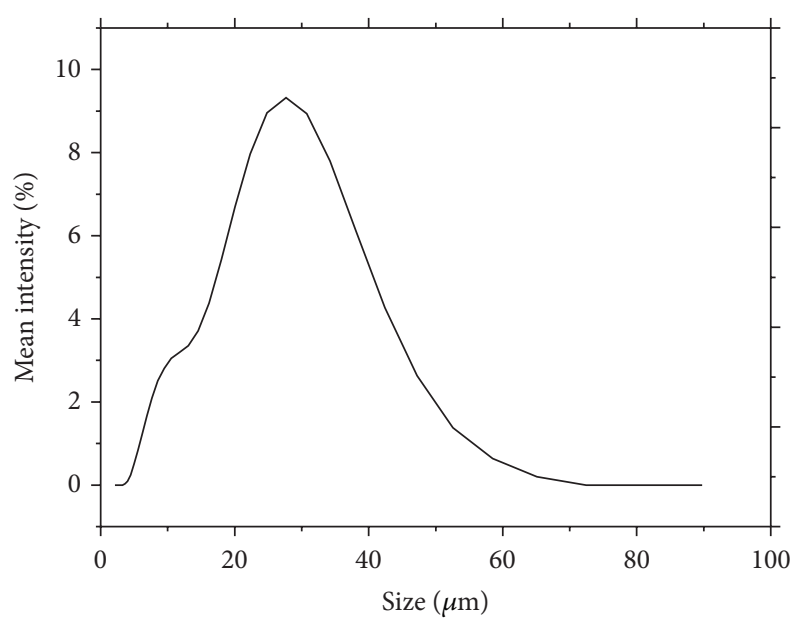

FIgURE 2: Particle size distribution of GHBs.

(2) Cement, fly ash, GHBs, and water were placed into the mixer (Table 2) and mixed for $2 \mathrm{~min}$. The relative viscosity of each fresh concrete was measured immediately after mixing. An appropriate amount of foam was subsequently added and mixed for 2 min until well-blended slurry was formed.

(3) The slurry was placed in a $100 \mathrm{~mm} \times 100 \mathrm{~mm} \times$ $100 \mathrm{~mm}$ or $300 \mathrm{~mm} \times 300 \mathrm{~mm} \times 30 \mathrm{~mm}$ mold, leveled by a steel ruler, and then placed in a room at $20 \pm 2^{\circ} \mathrm{C}$ with relative humidity $(\mathrm{RH})$ of $60 \%$. The specimens were removed from the molds after $24 \mathrm{~h}$ and stored in a fog room $\left(20 \pm 2^{\circ} \mathrm{C}\right.$; $\left.\mathrm{RH}>95 \%\right)$ for curing for $28 \mathrm{~d}$.

2.3. Test Methods. The shear stress of the specimens under different shearing rates was tested according to the test 
TABLE 2: Mix proportions of $400 \mathrm{~kg} / \mathrm{m}^{3} \mathrm{GHBFC}$.

\begin{tabular}{|c|c|c|c|c|c|c|}
\hline Mixes designation & Design density $\left(\mathrm{kg} / \mathrm{m}^{3}\right)$ & Cement (g) & Fly ash $(\mathrm{g})$ & GHBs (\%) & Water-binder ratio & Foam $(\mathrm{mL})$ \\
\hline $400-\mathrm{fa}$ & 400 & 1798 & 1199 & 0 & 0.60 & 5122 \\
\hline 400-g1 & 400 & 1774 & 1199 & 0.8 & 0.60 & 5122 \\
\hline $400-\mathrm{g} 2$ & 400 & 1750 & 1199 & 1.6 & 0.60 & 5122 \\
\hline $400-\mathrm{g} 3$ & 400 & 1726 & 1199 & 2.4 & 0.60 & 5122 \\
\hline $400-\mathrm{g} 4$ & 400 & 1702 & 1199 & 3.2 & 0.60 & 5122 \\
\hline $400-g 5$ & 400 & 1678 & 1199 & 4.0 & 0.60 & 5122 \\
\hline
\end{tabular}

Note: the mixing amount of GHBs means the percentage of the gross binder material by weight.

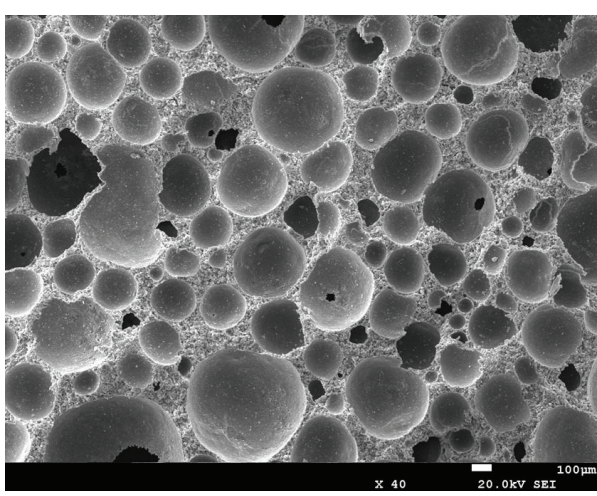

(a) Original image $\times 40$

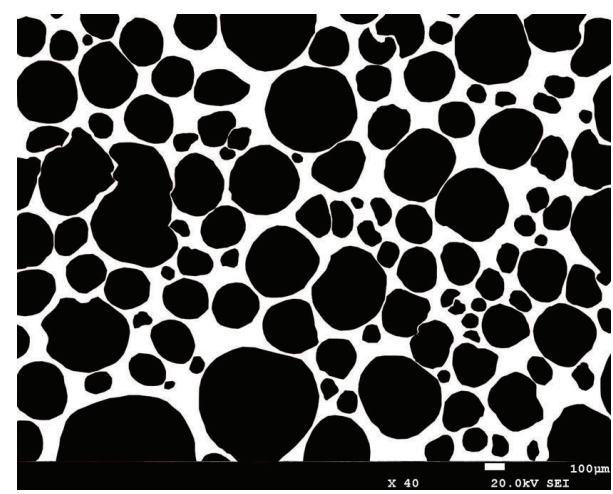

(b) Binarization processing image $\times 40$

FIGURE 3: SEM images of the foamed concrete specimens before and after binarization.

principle of non-Newtonian fluid viscosity by using a rotary viscometer (NXS-11A, Chengdu Instrument Factory, China). The Bingham model was used in linear fitting to determine the relationship between shear stress and shearing rate. The slope of the fitting curve represents the relative viscosity of the slurry (experiment parameters: laboratory temperature is $25^{\circ} \mathrm{C}$, A system).

The absolute dry density and true density of GHBFC were measured according to the Chinese Foamed Concrete standard (JG/T 266-2011) and Cement Density Measurement Method standard (GB/T 208-2014), respectively. The vacuum water absorption ratio of the test specimens was determined using an intelligent concrete vacuum water saturation instrument (Beijing Shengshi Weiye Science \& Technology Co., Ltd., China). The open porosity of GHBFC was calculated as follows:

$$
V_{\text {op }}=\frac{V_{\text {water }}}{V_{\text {sample }}} \times 100 \% \text {, }
$$

where $V_{\text {op }}, V_{\text {sample, }}$ and $V_{\text {water }}$ are the open porosity, the volume of test specimens, and the volume of water absorbed by the test specimens in vacuum state, respectively.

The compressive strength of the test specimens was measured by a fully automatic constant stress testing machine (JYE-300A, Beijing Jiwei Testing Instrument Co., Ltd., China) under a loading rate of $200 \mathrm{~N} / \mathrm{s}$. Slices $(8 \mathrm{~mm} \times 5 \mathrm{~mm} \times 5 \mathrm{~mm})$ of the test specimens were obtained from six directions. The reaction was terminated through hydration with absolute ethyl alcohol and dried in an oven at $60^{\circ} \mathrm{C}$ until a constant mass was obtained. The microstructures of the specimens were determined using a scanning electron microscope (SEM, Hitachi JSM-7500F). After binarization of the SEM images, Image-Pro Plus 6.0 was used to analyze and extract data on the pore characteristics of the specimens. Figure 3 shows the SEM images of the foamed concrete specimens before and after binarization. The mineral phases of the samples were identified through X-ray diffraction (XRD, DX2600) analysis, with $\mathrm{Cu}$ as target under continuous scanning at $5^{\circ}-70^{\circ}$ with a speed of $0.06^{\circ} / \mathrm{s}$. The thermal conductivity of the test specimens was determined by a thermal conductivity apparatus (JTRG-III, Beijing Century Jiantong Environmental Technology Co., Ltd.). The temperatures for the cold and hot plates were set as $5^{\circ} \mathrm{C}$ and $40^{\circ} \mathrm{C}$, respectively.

\section{Results and Discussion}

3.1. Influence of GHBs on Slurry Fluidity. The effect of GHB content on the rheological properties of slurry is shown in Figure 4 . The slope of the relational curve between shear stress and shearing rate represents the relative viscosity of the slurry. The calculated relative viscosities of 400-fa, 400-g1, 400-g2, 400-g3, 400-g4, and 400-g5 are 0.0274, 0.0267, 0.0238, 0.0203, 0.0196 , and $0.0133 \mathrm{~Pa} \cdot \mathrm{s}$ (Figure 4). The relative viscosity of the slurry decreases with increasing GHB content. The effect of GHB content on the slump flow of slurry is also shown in Figure 5. The fluidity increases with increasing GHB content.

These findings can be explained from two aspects. On the one hand, GHBs (K46) exhibit smooth surface and spherical shape compared with cement with sharp angles (Figure 1) and thus can improve slurry fluidity. On the other 
TABLE 3: Characteristics of air voids of the test specimens.

\begin{tabular}{lccccc}
\hline Specimens & Minimum diameter $(\mu \mathrm{m})$ & Maximum diameter $(\mu \mathrm{m})$ & Mean diameter $(\mu \mathrm{m})$ & Standard deviation & Variable coefficient \\
\hline $400-\mathrm{fa}$ & 39.07 & 698.3 & 203.2 & 139.7 & 0.512 \\
400 -g1 & 25.31 & 664.6 & 180.8 & 112.5 & 0.563 \\
400 -g2 & 37.74 & 569 & 179.8 & 103 & 0.266 \\
400 -g3 & 48.29 & 554 & 182.1 & 103.7 & 0.302 \\
400 -g4 & 40.42 & 546.6 & 170.5 & 97.53 & 0.281 \\
$400-\mathrm{g} 5$ & 21.93 & 494.3 & 140.5 & 86.6 & 0.389 \\
\hline
\end{tabular}

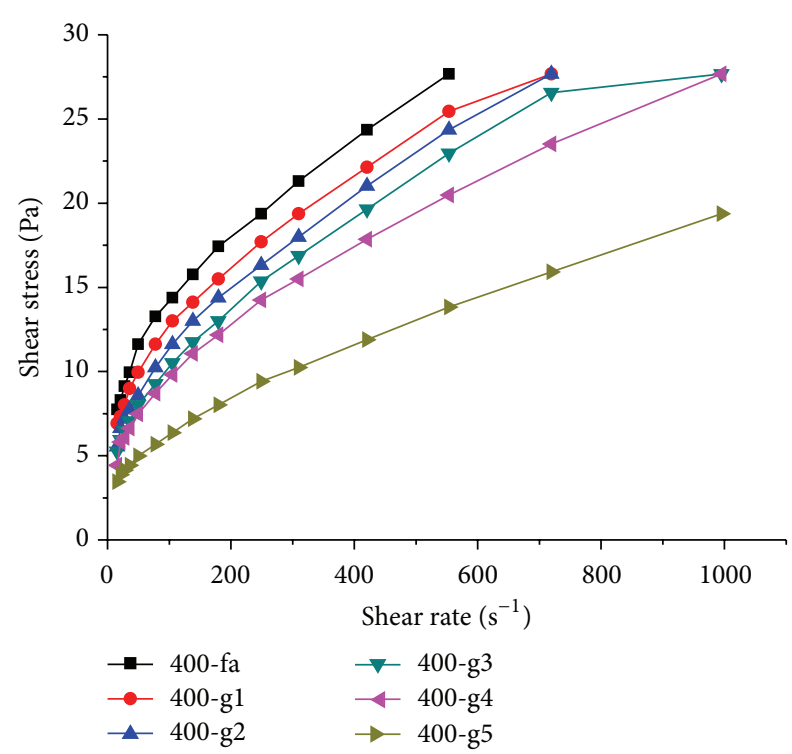

Figure 4: Effect of GHB content on the rheological properties of slurry.

hand, GHBs display larger length-diameter ratio and smaller specific surface area than those of cement. During mixing, the foamed concrete slurry mixed with GHBs, instead of cement, requires less water for surface wetting and contains high amounts of free water in the slurry system; this sample exhibits reduced relative viscosity and increased liquidity. This result indicates that slurry containing GHBs can improve the workability of foamed concrete.

\subsection{Effect of GHBs on Air-Void Features and Mechanism} Analysis. Figure 6 shows the SEM images of air voids in the specimens. The characteristics of air voids are obtained by Image-Pro Plus 6.0, and the results are shown in Table 3 and Figure 7. Table 3 shows that the average air-void diameter of the samples is negatively correlated with GHB content. Figure 7 shows that the proportions of small air voids $(<50 \mu \mathrm{m})$ of $400-\mathrm{fa}, 400-\mathrm{g} 1,400-\mathrm{g} 2,400-\mathrm{g} 3,400-\mathrm{g} 4$, and 400 -g5 are $6.38 \%, 7.26 \%, 3.97 \%, 0.79 \%, 2.10 \%$, and $10.42 \%$, respectively; the ratios of the relatively large air voids (400$1000 \mu \mathrm{m})$ in the above-mentioned samples are $9.58 \%, 4.84 \%$, $3.17 \%, 4.76 \%, 3.50 \%$, and $1.04 \%$, respectively. The ratios of air voids $(50-400 \mu \mathrm{m})$ that determine the strength values of $400-$ fa, 400-g1, 400-g2, 400-g3, 400-g4, and 400-g5 are $84.04 \%$, $87.90 \%, 92.86 \%, 94.44 \%, 94.41 \%$, and $88.54 \%$, respectively. This finding is attributed to the GHBs surface, which exhibits

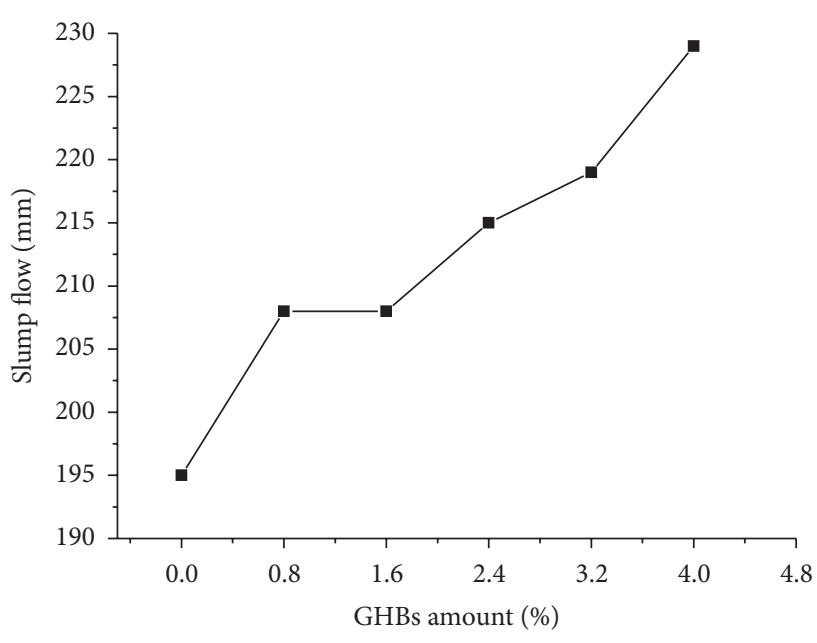

FIGURE 5: Effect of GHB content on the slump flow of slurry.

high water absorption capacity and fast water absorption [19]. Thus, GHBs can provide sufficient water for hydration of adjacent cement particles, thereby reducing the initial setting time of cement on air-void walls, solidifying bubbles, and inhibiting surface tension-induced bubble growth during curing. As such, the ratios of small and large air voids within the foamed concrete decrease with increasing GHB content, and the distribution of air voids becomes centralized and uniform. Excessive GHBs may absorb excessive volume of water from the surface of adjacent bubbles and reduce the stability of bubbles, thereby inducing bubbles to divide into some smaller ones. This phenomenon increases the number of small air voids after setting and hardening of the foamed concrete slurry.

3.3. Influences of GHB on Porosity and Strength. Table 4 shows the correlation between porosity and compressive strength of the test specimens. The $28 \mathrm{~d}$ compressive strength values of 400-fa, 400-g1, 400-g2, 400-g3, 400-g4, and 400-g5 are $1.80,1.89,1.97,2.39,2.26$, and $2.05 \mathrm{MPa}$, respectively. The compressive strength increases first, reaches its peak $(2.39 \mathrm{MPa})$ at $2.4 \mathrm{wt} \%$, and then decreases. The compressive strength of the foamed concrete increases and the open porosity gradually decreases when the GHB content increases from $0 \mathrm{wt} \%$ to $2.4 \mathrm{wt} \%$. Compared with $400-\mathrm{fa}, 400 \mathrm{-g} 3$ achieves $32.8 \%$ higher strength and $8.37 \%$ lower open porosity. The compressive strength of the foamed concrete decreases and the open porosity increases when the GHB content exceeds 
TABLE 4: The correlation between porosity and compressive strength of the test specimens.

\begin{tabular}{lcccc}
\hline Specimens & Dry density $\left(\mathrm{kg} / \mathrm{m}^{3}\right)$ & Open porosity $(\%)$ & Closed porosity $(\%)$ & 28 d compressive strength $(\mathrm{MPa})$ \\
\hline $400-\mathrm{fa}$ & 406.5 & 46.07 & 36.25 & 1.80 \\
$400-\mathrm{g} 1$ & 413.0 & 44.20 & 38.92 & 1.89 \\
$400-\mathrm{g} 2$ & 413.5 & 43.05 & 39.30 & 1.97 \\
$400-\mathrm{g} 3$ & 445.0 & 37.70 & 43.40 & 2.39 \\
$400-\mathrm{g} 4$ & 426.5 & 43.95 & 38.69 & 2.26 \\
$400-\mathrm{g} 5$ & 435.5 & 45.05 & 36.20 & 2.05 \\
\hline
\end{tabular}

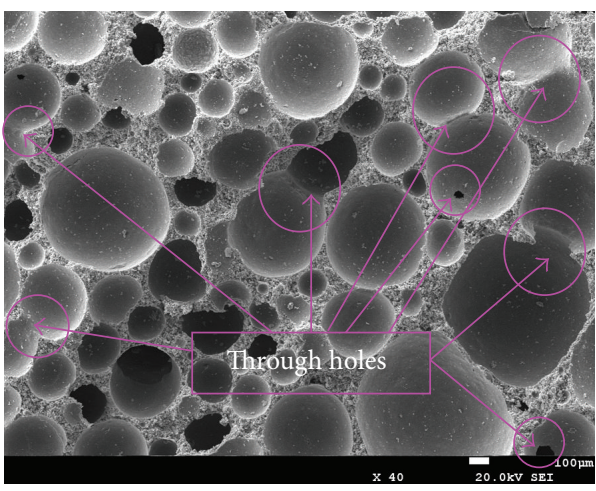

(a) $400-\mathrm{fa} \times 40$

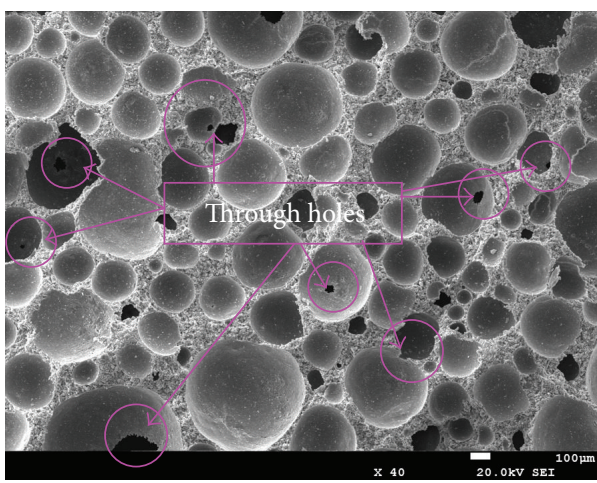

(c) $400-\mathrm{g} 2 \times 40$

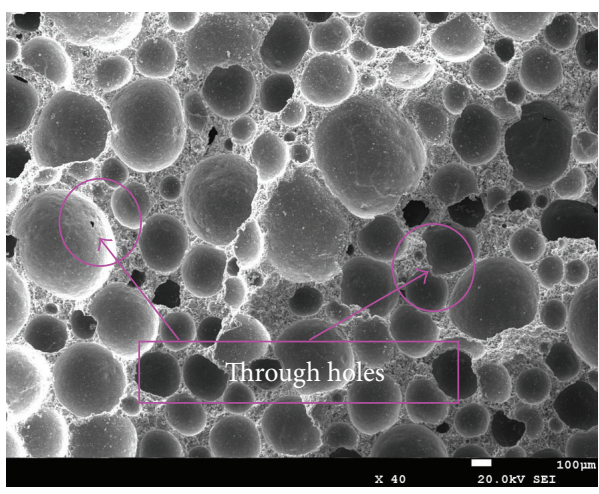

(e) $400-\mathrm{g} 4 \times 40$

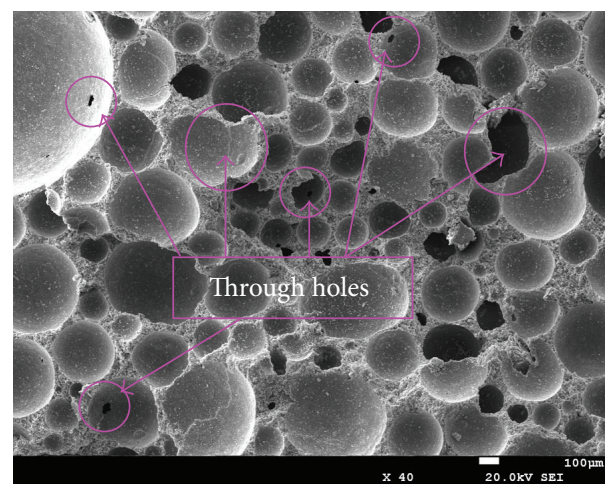

(b) 400 -g1 $\times 40$

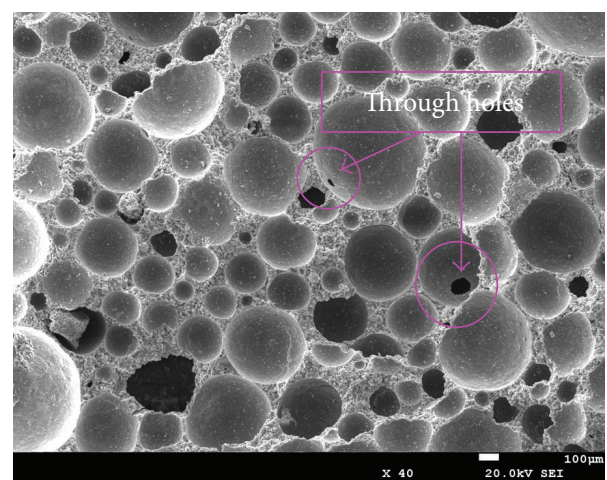

(d) 400 -g $3 \times 40$

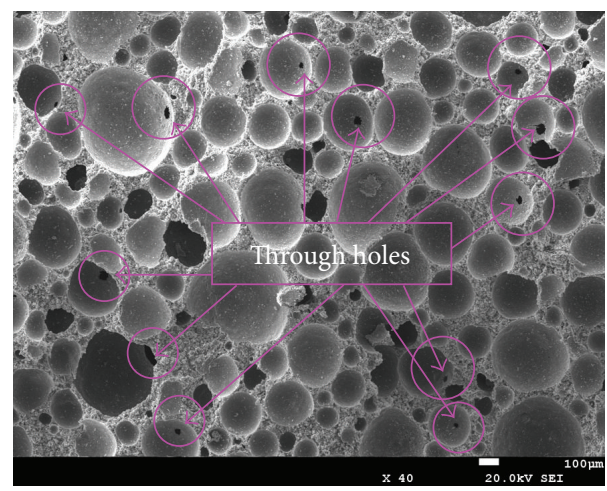

(f) 400 -g5 $\times 40$

FIGURE 6: SEM images of air voids in the specimens.

$2.4 \mathrm{wt} \%$. GHBs exhibit a hollow structure and closed pores and form closed air voids after being added to foamed concrete, as manifested by increase in closed air voids and decrease in open air voids in 400-g1, 400-g2, and 400-g3. Excessive GHB content ( $>2.4 \%$ ) produces high proportions of small air voids in the foamed concrete (Section 3.2, 400-g5 $<50 \mu \mathrm{m}$ ) and excessively large surface area of air voids; thus, high amounts of cement paste are required to cover the air voids. Under the same cement dosage, the walls between air voids in concrete with excessive GHBs are relatively thin and 


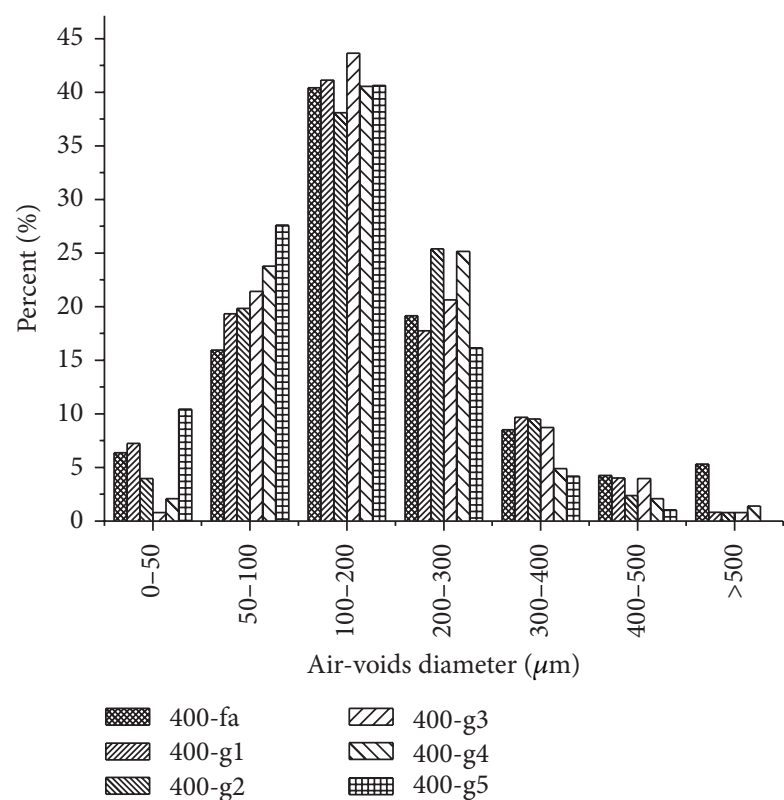

FIGURE 7: Effects of GHBs on air-voids diameter distribution of the test specimens.

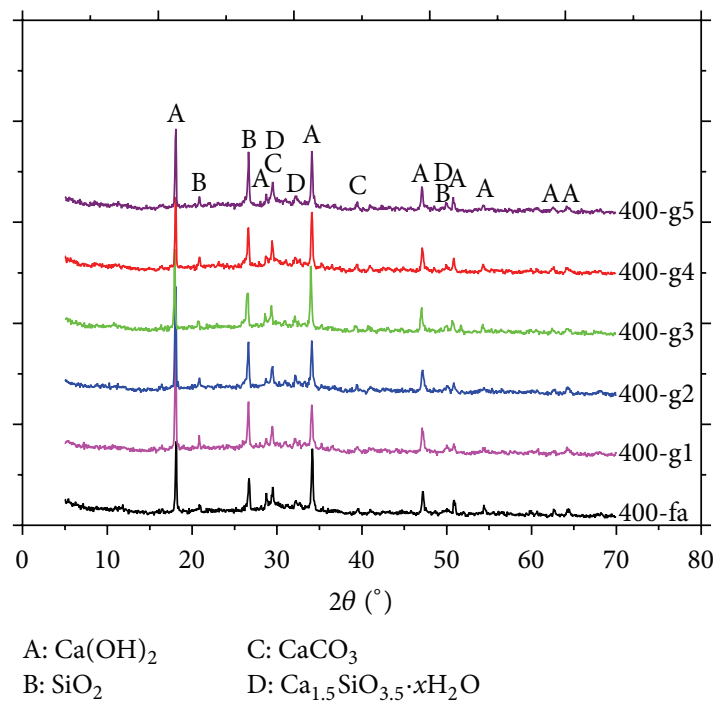

FIGURE 8: XRD patterns of the test specimens.

through holes are easily formed. At this point, the total open porosity of 400 -g 4 and 400 -g 5 begins to increase, whereas the strength begins to decline.

The XRD patterns of the test specimens are depicted in Figure 8, which shows that the pore walls of GHBFC generated through cement hydration are mainly composed of $\mathrm{Ca}(\mathrm{OH})_{2}, \mathrm{C}-\mathrm{S}-\mathrm{H}$ gel, and $\mathrm{CaCO}_{3}$. The $\mathrm{SiO}_{2}$ from GHBs does not participate in the hydration reaction during curing for $28 \mathrm{~d}$.

Figure 9 shows the SEM images of the pore walls of the test specimens. Figure 9(a) shows that the pore wall without GHBs consists of cross-linked hydration products and numerous micropores. Figures 9(b) and 9(c) show the SEM images of the pore walls of the test specimens with GHBs, which are compactly covered by the hydration products of cement.

From the perspective of material structure, primary factors that influence the compressive strength of foamed concrete include the structures of pore walls and air voids. Figures 9(b) and 9(c) show that some micropores formed during cement hydration are replaced by high-strength GHBs with dense surface; thus, the pore wall of foamed concrete becomes denser, and the compressive strength improves. Low GHB content $(\leq 1.6 \%)$ insignificantly affects the densification of pore walls and increases the number of through holes (Figures 6(b) and 6(c)). This phenomenon explains slight improvement in the compressive strength of 400-g1 and 400g2. When the GHB content ranges from $2.4 \%$ to $3.2 \%$, the pore walls become dense and few through holes are formed (Figures 6(d) and 6(e)). This finding indicates the outstanding reinforcement of the compressive strength of GHBFC. On the other hand, previous research [20] concluded that a narrow distribution of air-void diameter contributes to an even airvoid diameter, high wall density, low open porosity, and high compressive strength of foamed concrete. As shown in Section 3.2, the average air-avoid diameter of the samples decreases gradually with increasing GHB content, which in turn increases the compressive strength of foamed concrete. Nevertheless, the amount of small air voids $(<50 \mu \mathrm{m})$ in 400 g5 reaches as high as $10.42 \%$, resulting in high total specific surface area of air voids and high demand for cement paste to cover the pores. Under the same cement content, the wall between pores is relatively thin and the amount of through holes increases (Figure 6(f)), resulting in the highest degree of open porosity and a considerable loss in strength. This finding demonstrates that excessive GHBs reduce compressive strength. In addition, this result indicates that GHBs play a vital role in improving the compressive strength of foamed concrete and an optimum GHB content must be applied.

3.4. Effects of GHBs on Thermal Conductivity. The effects of GHBs on thermal conductivity of the test specimens are depicted in Figure 10. The thermal conductivity decreases with increasing GHB content. The thermal conductivity of 400-g3, which displays the highest compressive strength, is $0.0936 \mathrm{w} /(\mathrm{m} \cdot \mathrm{k})$, whereas the thermal conductivity of 400 g5 exhibits the highest GHB content of $0.0907 \mathrm{w} /(\mathrm{m} \cdot \mathrm{k})$. The thermal conductivity of a material is mainly determined by the size, quantity, shape, and interconnections of its pores [13]. A large number of small closed pores can effectively reduce air convection. Convective heat transfer between the pores via air is difficult because of the completely hollow porous structure of the GHB particles. The number of closed pores in the foamed concrete increases with increasing GHB content, resulting in decreased thermal conductivity.

\section{Conclusions}

In this study, the effect of GHB content on the properties of GHBFC was investigated, and the results can be summarized as follows: 


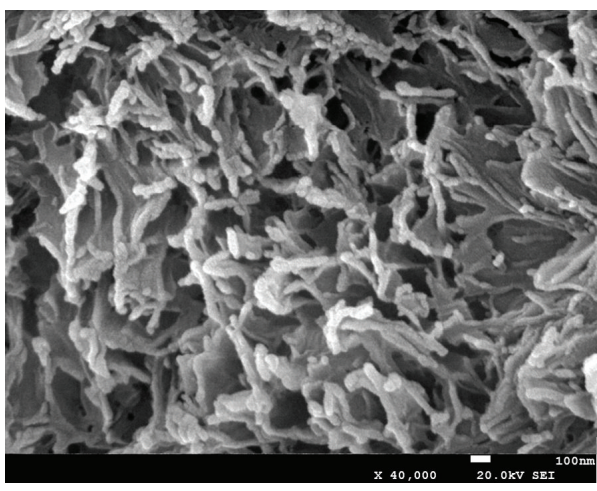

(a) $400-\mathrm{fa} \times 40,000$

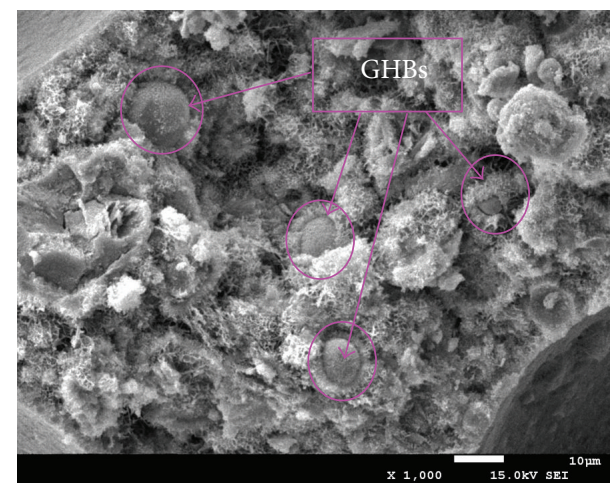

(b) $400-$ g3 $\times 1,000$

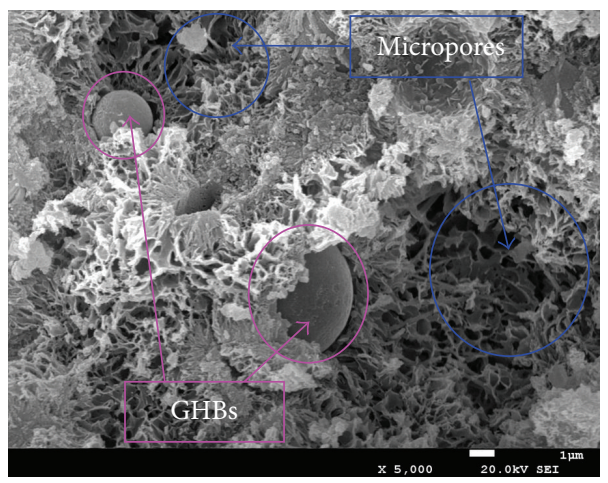

(c) $400-\mathrm{g} 3 \times 5,000$

FIGURE 9: SEM images of the pore walls of the test specimens.

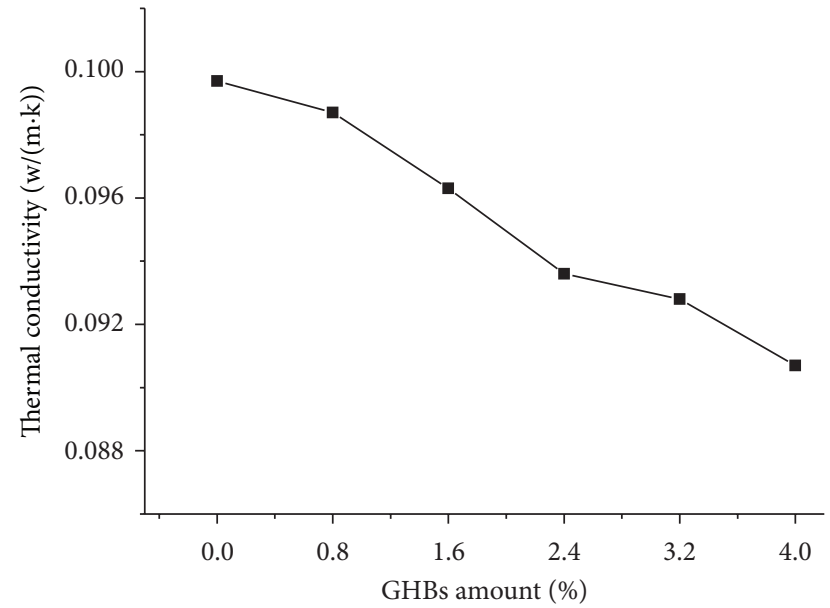

FIGURE 10: Effects of GHBs on thermal conductivity of the test specimens.

(1) GHBs can reduce the relative viscosity and improve the workability of cement slurry.

(2) A proper amount of GHBs mixed into a foamed concrete can significantly improve the compressive strength and narrow the distribution of air voids. Excessive GHB content would increase small air voids
$(<50 \mu \mathrm{m})$, resulting in a high degree of open porosity in the hardened foamed concrete.

(3) GHBs can reduce convective heat transfer through air, enhancing the thermal insulation of GHBFC.

\section{Competing Interests}

The authors declare that they have no competing interests.

\section{Acknowledgments}

This work was supported by the Plan Program for Science and Technology of Sichuan Province (no. 2015GZ0245), the Program for Innovation Research Team Development Plan with Rolling Support of the Ministry of Education (no. IRT14R37), and the Postdoctoral Science Foundation of Sichuan Province.

\section{References}

[1] Z. Huang, T. Zhang, and Z. Wen, "Proportioning and characterization of Portland cement-based ultra-lightweight foam concretes," Construction and Building Materials, vol. 79, pp. 390-396, 2015.

[2] G. Indu Siva Ranjani and K. Ramamurthy, "Behaviour of foam concrete under sulphate environments," Cement and Concrete Composites, vol. 34, no. 7, pp. 825-834, 2012. 
[3] S. Wei, C. Yiqiang, Z. Yunsheng, and M. R. Jones, "Characterization and simulation of microstructure and thermal properties of foamed concrete," Construction and Building Materials, vol. 47, no. 10, pp. 1278-1291, 2013.

[4] X. Chen, Y. Yan, Y. Liu, and Z. Hu, "Utilization of circulating fluidized bed fly ash for the preparation of foam concrete," Construction and Building Materials, vol. 54, no. 3, pp. 137-146, 2014.

[5] R. M. Ahmed, N. E. Takach, U. M. Khan et al., "Rheology of foamed cement," Cement and Concrete Research, vol. 39, no. 4, pp. 353-361, 2009.

[6] X. Tan, W. Chen, Y. Hao, and X. Wang, "Experimental study of ultralight $\left(<300 \mathrm{~kg} / \mathrm{m}^{3}\right)$ foamed concrete," Advances in Materials Science and Engineering, vol. 2014, Article ID 514759, 7 pages, 2014.

[7] J. Z. Liang and F. H. Li, "Measurement of thermal conductivity of hollow glass-bead-filled polypropylene composites," Polymer Testing, vol. 25, no. 4, pp. 527-531, 2006.

[8] N. Xu, J. Dai, Z. Zhu, X. Huang, and P. Wu, "Synthesis and characterization of hollow glass-ceramics microspheres," Ceramics International, vol. 37, no. 7, pp. 2663-2667, 2011.

[9] L. Zhao, W. Wang, Z. Li, and Y. F. Chen, "An experimental study to evaluate the effects of adding glazed hollow beads on the mechanical properties and thermal conductivity of concrete," Materials Research Innovations, vol. 19, pp. S5929-S5935, 2015.

[10] W. Wang, L. Zhao, Y. Liu, and Z. Li, "Mechanical properties and stress-strain relationship in axial compression for concrete with added glazed hollow beads and construction waste," Construction and Building Materials, vol. 71, pp. 425-434, 2014.

[11] T. S. Yun, Y. J. Jeong, T.-S. Han, and K.-S. Youm, "Evaluation of thermal conductivity for thermally insulated concretes," Energy and Buildings, vol. 61, pp. 125-132, 2013.

[12] S.-Y. Chung, T.-S. Han, S.-Y. Kim, J.-H. Jay Kim, K. S. Youm, and J.-H. Lim, "Evaluation of effect of glass beads on thermal conductivity of insulating concrete using micro CT images and probability functions," Cement and Concrete Composites, vol. 65, pp. 150-162, 2016.

[13] Z. Li and Y. Li, "Experiment on mix proportion of glazed hollow beads insulating mortar and its mechanism analysis," New Building Material, vol. 38, no. 2, pp. 46-48, 2011.

[14] L. Chenglou and K. Gongxiang, "Preparation of phase-change energy-storage flexible thermal insulation exterior coatings," Architectural Coatings and Application, vol. 26, no. 11, pp. 35-39, 2011.

[15] X.-L. Qu and X.-G. Zhao, "Component effect on drying shrinkage of glazed hollow bead thermal insulation mortar," Journal of Materials Science \& Engineering, vol. 33, no. 2, pp. 283-287, 2015.

[16] G. Ma, Y. Zhang, and Z. Li, "Influencing factors on the interface microhardness of lightweight aggregate concrete consisting of glazed hollow bead," Advances in Materials Science and Engineering, vol. 2015, Article ID 153609, 15 pages, 2015.

[17] W. Zhao, H. Yang, M. Chen, P. Yang, and J. Yang, "Measurement of specific thermal/thermal conductivity coefficient of porous expanded pearlite concrete and evaluation of heat preservation property," New Building Material, vol. 38, no. 1, pp. 78-80, 2011.

[18] B. Chen and N. Liu, "A novel lightweight concrete-fabrication and its thermal and mechanical properties," Construction and Building Materials, vol. 44, no. 7, pp. 691-698, 2013.

[19] L. Zhao, Key research issues of glazed hollow bead insulation concrete applied to real buildings [Ph.D. dissertation], Tai Yuan University of Technology, 2015 (Chinese).
[20] J. Jiang, Z.-Y. Lu, and Y.-H. Niu, "Effect of water reducing agent on air-void structure and properties of ultra-lightweight foamed concrete," Journal of Wuhan University of Technology, vol. 36, no. 11, pp. 25-31, 2014. 

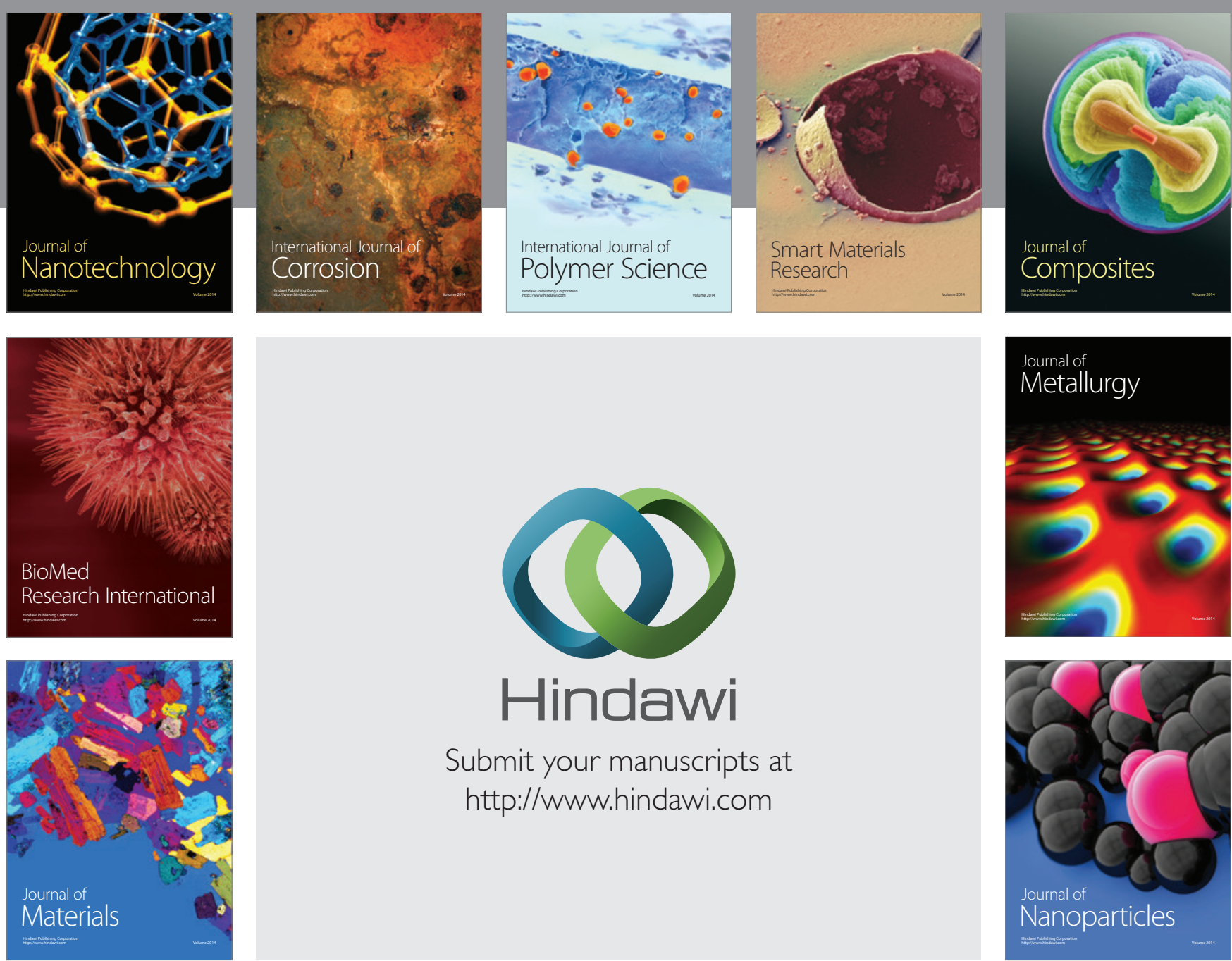

\section{Hindawi}

Submit your manuscripts at

http://www.hindawi.com

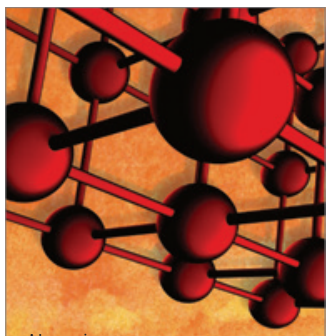

Materials Science and Engineering
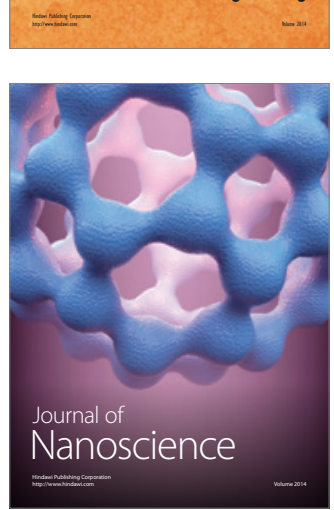
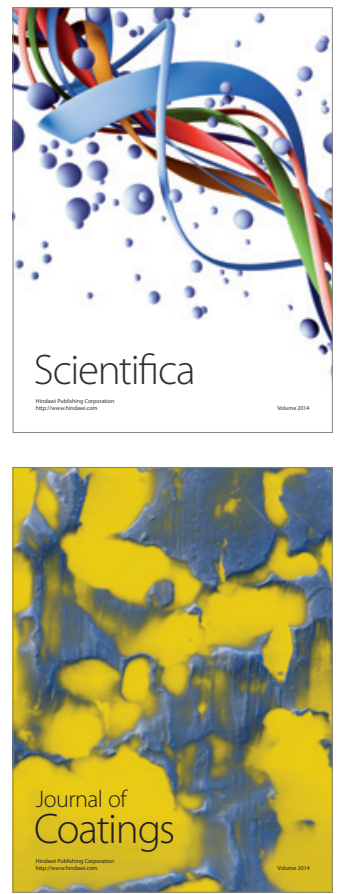
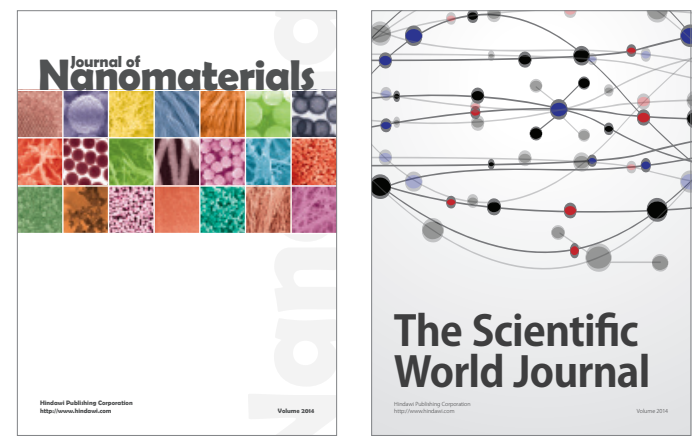

The Scientific World Journal
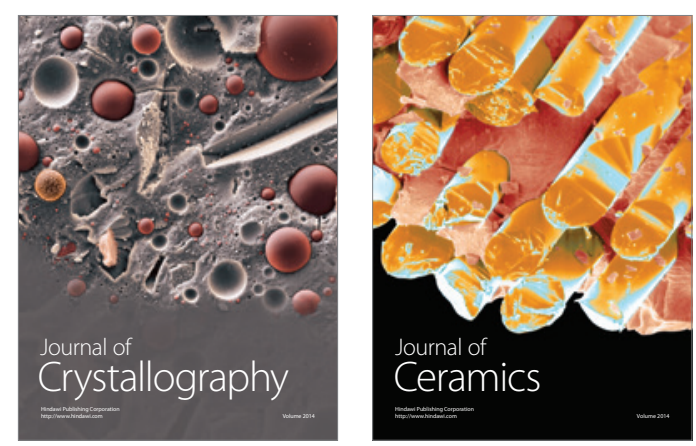
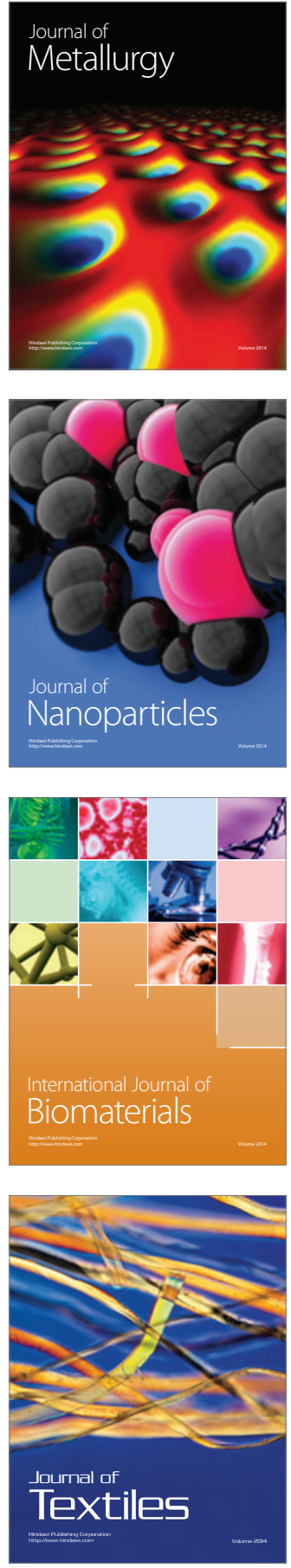